\title{
A framework to assess the social and economic impacts on communities and industries due to loss in serviceability of infrastructure networks after floods
}

\author{
A. Deshmukh, E. H. Oh \& M. Hastak \\ Construction Engineering \& Management, School of Civil Engineering, \\ Purdue University, USA
}

\begin{abstract}
The functioning of communities and industries depends on the infrastructure network. Daily activities (such as production, shipping, supply chain, etc., for industries and commuting to work, business, schooling, etc., for communities) are performed efficiently with the help of the infrastructure network. It is vital for the infrastructure to function efficiently at all times. However, during disasters, either manmade or natural, the functioning or serviceability of the infrastructure could be severely affected. This in turn has an impact on the activities/services of communities and industries. These activities and services contribute socially and economically. When their functioning is affected and usually reduced in the case of disasters, their social and economic contribution is reduced. This reduction can be assessed as social and economic impact on communities and industries due to reduction in serviceability of the infrastructure network. This paper presents a framework that establishes a relationship between the services and activities of communities and industries and infrastructure. The paper also provides a unique approach to assess social and economic impacts due to serviceability reduction of infrastructure after floods. The framework is a step towards providing valuable information for decision making during the quick recovery phase after disaster.

Keywords: floods, disaster risk reduction, severity, critical infrastructure, social and economic impacts.
\end{abstract}




\section{Introduction}

Hurricanes, earthquakes and floods are some of the natural disasters that have extreme social and economic impact on communities and industries. Hurricane Katrina in 2005 damaged the city of New Orleans, 1400 people lost their lives and the losses were estimated between $\$ 70$ to $\$ 125$ billion (Wildasin [25]). The levee failure in the case of Hurricane Katrina caused other lifeline infrastructures, such as transportation systems, electricity, water and waste water, to fail, which had a debilitating impact on New Orleans. The June 2008 Midwest floods in the United States are identified as one of the worst flooding after 1993 Midwest floods causing damage in states of Iowa, Illinois, Missouri and Indiana. The flood destroyed huge areas of farmland impacting the corn and soybean industry of the Midwest. Although the reason behind the floods was extreme precipitation, the damage was further increased by failure of infrastructures, such as levee failures and collapse of roads and rail road bridges as in case of Cedar Rapids. It therefore becomes important to identify and understand the role of infrastructure in providing social and economic support to industries and communities, as well as protect important or critical infrastructure for achieving the following objectives: 1) Preparation of efficient mitigation strategies and rapid relief response soon after the disaster. 2) Help in sustaining the activities of communities and industries in pre/during/post phases of the flood.

\section{Objective and scope}

The objective of this paper is to assess the severity of flood impact on affected communities and industries in reliance with critical infrastructure in terms of social and economic impact. This would enable the city managers and emergency response teams to identify and protect critical infrastructures and minimize the impact on communities and industries. This research proposes a framework to assess the social and economic impact of floods on communities and industries based on the interrelationship with critical infrastructures. The proposed model would enable the experts to identify areas of greatest need so that proper resources can be allocated to reduce social and economic vulnerability.

\section{Previous research}

\subsection{Technical impacts}

Rinaldi et al. [21] classified infrastructure as complex adaptive systems (CAS) and identified the interdependencies among them. However, they suggest that the defined interdependency among infrastructures needs metrics, which include social and economic factors, that can clearly explain the risk of failure. Limited research has been conducted to evaluate the impact on communities and industries in reliance with critical infrastructures that act as social and economic systems due to disasters (Simpson et al. [23]). They have proposed a framework 
that combines engineering knowledge with social and economic data using fragility curves to estimate the impact of natural hazards.

\subsection{Economic impact}

Several studies discuss the impact of a single infrastructure system on a regional economy. Burrus et al. [1] have developed a full-day equivalents lost (FDEL) metric to measure the impact of frequent business interruption due to lowintensity hurricane regions. Chang et al. [3] applied a simulation approach to model the linkage between physical infrastructure systems and the urban economy. In addition, Chang [2] has developed a framework for extended life cycle cost analysis to evaluate mitigation strategies for lifeline systems, such as electric power, water and transportation.

Rose et al. [22] have proposed a static, regional CGE (computable general equilibrium) simulation model to estimate economic losses in regional economy due to disruptions in electricity. Whereas, Yang et al. [26] have proposed a conceptual framework of a business impact model to understand impacts due to input disruption, such as equipment damage, building damage, workforce losses, loss of customers, and loss of finished goods. Lian et al. [8] have suggested the significance of interdependency among various sectors of the industry and the impact of functional disruptions in critical infrastructure systems.

\subsection{Social impact}

Tapsell et al. [24] suggest that current research methods on assessing losses due to floods can estimate economic gains and losses but are unable to capture the degraded life quality after floods. Lindell et al. [10] illustrated the relationship of physical and social impacts of natural disasters on communities and emphasized the need for research to identify social and economic characteristics of communities.

With an increase in socioeconomic losses due to natural disasters more emphasis is being placed on improved risk management strategies that consider both social as well as monetary loss, Munich-Re [14], Cutter et al. [4] and Dwyer et al. [5] and Lin et al. [9] have developed a vulnerability indices to measure social vulnerability in communities. Picou and Cecelia [20] analyzed the impact of Hurricane Ivan and constructed a scale combined with the intrusive and cognitive variables to apply a multiple regression statistical model. However, the research does not capture the role and importance of critical infrastructure in pre/during/post disaster.

Mantell [11] suggest that existing economic impact models are complex and use time based econometric data. Such models therefore are unable to provide an assessment soon after the disaster. Therefore, a need arises for developing impact models that use relevant ephemeral data and are based on inter relationship existing between communities, industries and related critical infrastructure for not only assessing social and economic impacts but also help in developing rapid response mitigation strategies. 


\section{Data collection efforts}

Previous research has indicated that the relevant impact data is best collected soon after the occurrence of the disaster (Oh and Hastak [16]). Thus, it is important to start characterizing the damage in any disaster affected region as soon as possible. To identify the impact of the disaster, in-depth investigation of impact data is needed to include accurate locations and circumstances of damaged infrastructure, the level of damage (or serviceability of damaged infrastructure), and duration of service failure of damaged infrastructure within the affected communities. The characteristic of such data is ephemeral and it is likely to vanish as time goes by. This is primarily so because of the following reasons:

- The recovery response efforts consist of activities such as site clearance and rehabilitation efforts which cause loss of relevant data from the site before it can be collected.

- Post disaster recovery efforts often lead to frequent migration of victims in search of basic amenities making the vital social and economic impact data difficult to collect.

Oh et al. $[18,19]$ have recommended two step data collection. The primary data collection should include the ephemeral and detailed data collection through interviews of involved parties like public agencies, industries, and communities which is then synthesized into technical, social and economic impact of floods. This is followed by questionnaire survey that is sent out to collect relevant ephemeral data due to damaged or destroyed infrastructure.

The authors have conducted successful data collection in the affected areas of June 2008 Midwest floods with support from NSF through a NSF SGER: A Short-term Site Investigation of the 2008 Midwest Floods. The purpose of the SGER project was to conduct in-depth case studies in the affected regions to obtain the ephemeral data with respect to the affected infrastructure and related industries and communities. Site-investigations were conducted at various affected cities like Gulfport, Illinois; Cedar Rapids, Iowa; and St. Louis, Missouri to collect damage information including time sensitive ephemeral data (i.e., data that might vanish soon after the occurrence of a flood).

\section{Framework for social and economic impact assessment}

To understand the inter-relationship between critical infrastructure, industries, and communities, it is important to define their relationships and impacts considering various economic, social and technical factors. Oh et al. [17] proposed a basic cell model of disaster impact mechanism to analyze the flow of impact of natural disasters on infrastructure, communities and industries. However, the defined relationship addresses technical issues only which needs to be further extended to include social and economic issues as well.

The model establishes a relationship between infrastructure, communities and industries which is based on the fact that activities and services of communities and industries are sustained by services offered by critical infrastructure. For 
example, activity production for industries might be supported by critical infrastructure such as electricity, water, etc., and for communities, activity like commuting to work place might be supported by transportation systems such as roads, railroads, etc. During a disaster, the services of critical infrastructure such as electric supply, water supply, gas, transportation, etc., are either reduced in their serviceability or completely shut down.

A conceptual framework is proposed to understand the flow of impact between infrastructure, communities and industries due to disasters (Fig 1). The flow of impact of natural disaster on infrastructure and communities and industries can be classified as primary impact which leads to physical damage on communities, industries and infrastructure. The direct impact leads to reduction or failure of services of critical infrastructure.

Direct impacts usually occur during the disaster events damaging the critical infrastructure physically which influences the social and economic assistance offered to the activities of communities and industries in the form of benefits Reduction in these benefits results in social and economic impact. Thus, social and economic impact can be defined as:

- Social Impact: Effect of failure of services of critical infrastructure on communities and industries in terms of social aspects, i.e. social surroundings of an individual or a family.

- Economic Impact: Effect of failure of services of critical infrastructure on the economic activities of communities and industries in terms of economic aspects.

Critical infrastructure supports the activities of communities and industries for their sustenance. Indirect losses such as production losses arise due to infrastructure disruptions during disasters (Hiete and Merz [7]). They have

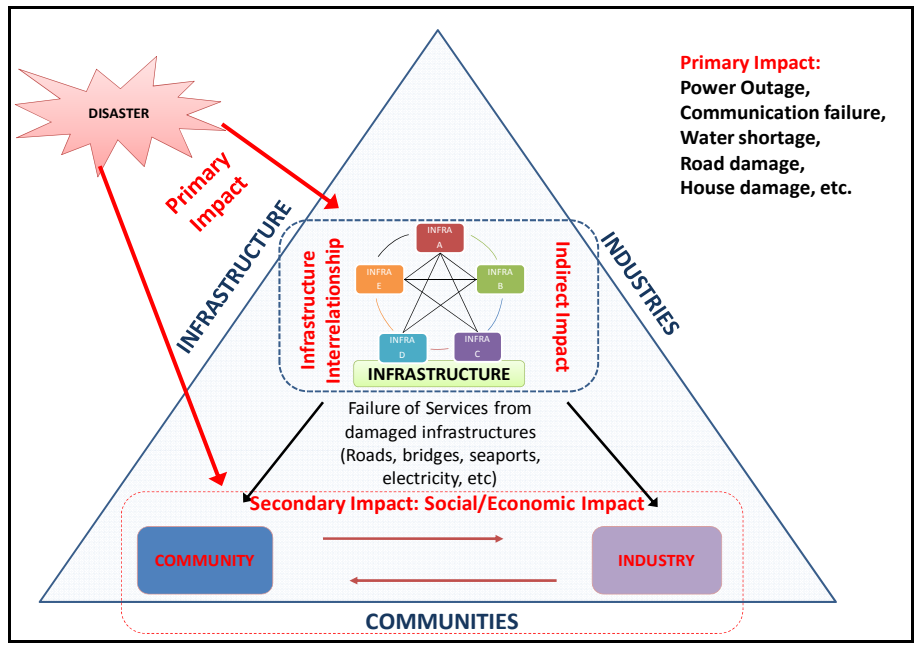

Figure 1: A conceptual framework of disaster impact. 


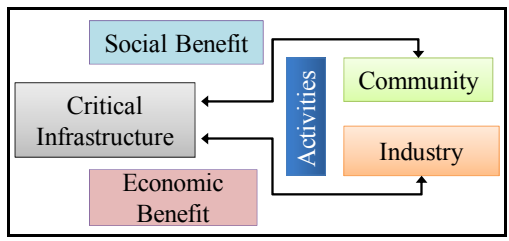

Figure 2: $\quad$ Activities as impact measurement factors.

proposed a framework to assess the vulnerability of industrial sectors towards disaster losses. Dependencies that exist between function of industry such as production and its dependency on infrastructure is signified in the proposed framework. Activities are important for an industry to grow their economy and for communities to not only be economically stable but to be socially well equipped. Activities of communities and industries contribute socially and economically and can be used as impact measurement factors for social and economic impact assessment (Fig 2). Communities and industries are nested in infrastructure networks and alternates for similar infrastructure types may exist for sustaining a particular activity offering different social and economic benefits to that activity. However, the benefits achieved from using either of the alternatives are likely to be different. Similarly, a community might use two different routes for commuting to a work place where both the routes will offer different benefits.

In case of a disaster event such as flood, the activities will get impacted indirectly due to failure of services of related critical infrastructure. The services offered by critical infrastructure reduce to a certain level of serviceability. The activities will have a reduction in the social and economic benefit offered by such critical infrastructure.

This reduction in benefits for communities and industries due to reduced level of serviceability of critical infrastructure can be assessed as social and economic impacts due to disaster events. Social and economic impact assessment for communities and industries can be made if:

- Serviceability level of the related critical infrastructure is known after a disaster.

- A relationship between social and economic benefit for activities of communities and industries and serviceability level of related critical infrastructure could be established.

Oh et al. [19] proposed a DSS (Decision Support System) to plan region specific emergency response and mitigation strategies based on the relationship between communities, industries and related critical infrastructure. The DSS was developed based on the data collected from 2008 Midwest Flood affected areas in the US. The results are derived from ephemeral data collection in the form of technical, social and economic aspects and analyzed in terms of criticality, vulnerability and severity, which are identified as key metrics for the DSS. Based on DSS, a framework for social and economic impact assessment is 


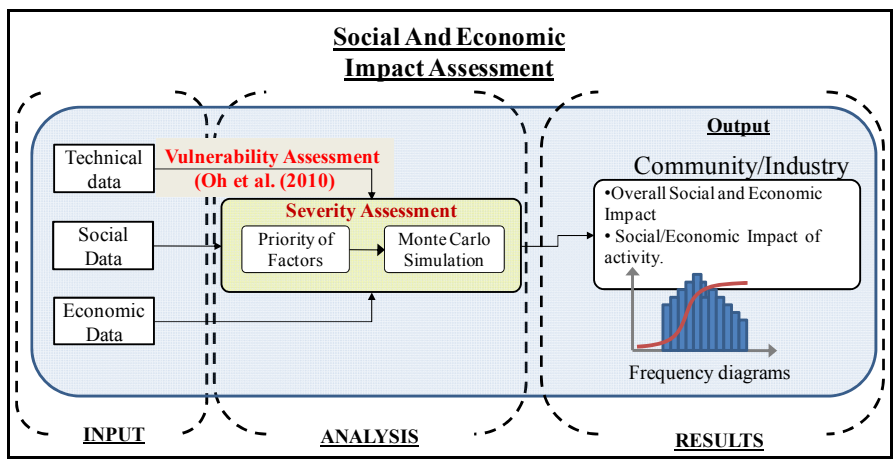

Figure 3: $\quad$ Social and economic impact assessment.

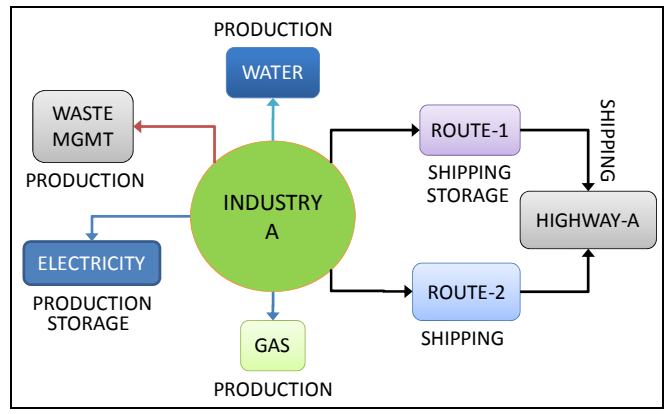

Figure 4: Interrelationship diagram of industry A with supported activities.

proposed for communities and industries with reliance to critical infrastructure (Fig 3). The proposed framework is explained through a hypothetical situation where an industry in a town is impacted by a flood event.

"Industry A" situated in a town is impacted by floods. Soon after the floods, relevant ephemeral data is collected from city engineers and people from industry through personal interviews, survey questionnaire and site investigation in terms of technical, social and economic aspects.

Activities of industry A depend on critical infrastructure for their sustenance (Fig. 4). As shown in Table 1, they are prioritized through pairwise comparison method in pre-flood situation and are rated using a relative scale of importance for their economic contribution to the industry (Hastak and Shaked [6]). The relative scale of importance/assistance is shown below:

- Very High (VH): 1.5

- High (H): 1.25

- $\operatorname{Medium}(\mathrm{M}): 1.0$

- Low (L): $1 / 1.25=0.8$

- Very Low (VL): $1 / 1.5=0.67$

For example, "finance" when compared to "storage" is given a rating of 1.25 where as when compared to "production", is given a rating of 1.0. The 
Table 1: $\quad$ PWC method for activity prioritization.

\begin{tabular}{|l|c|c|l|l|}
\hline ACTIVITY & \multicolumn{2}{|c|}{$\begin{array}{l}\text { PAIRWISE } \\
\text { COMPARISON }\end{array}$} & $\begin{array}{l}\text { IMPORTANCE } \\
\text { LEVEL } \\
\text { ASSESSMENT }\end{array}$ & $\begin{array}{l}\text { NORM. LVL. OF } \\
\text { IMPORTANCE }\end{array}$ \\
\hline STORAGE & 1.00 & - & 1.00 & 0.64 \\
\hline FINANCE & 1.25 & 1.00 & 1.25 & 0.80 \\
\hline PRODUCTION & 1.00 & 1.25 & 1.56 & 1.00 \\
\hline COMMUTING & 0.67 & 1.00 & 1.05 & 0.67 \\
\hline SHIPPING & - & 1.25 & 1.31 & 0.84 \\
\hline \multicolumn{6}{|c|}{ Maximum Importance $=1.56$} & \\
\hline
\end{tabular}

normalized level of importance for "finance" is calculated to be $80 \%$ (i.e., $1.25 / 1.56)$. The ratings are normalized with respect to best score. As shown in Fig. 4, "shipping" is supported by Route-1 and Route-2. However, the economic assistance provided by Route- 1 and Route- 2 would be different (Route- 1 might be an interstate highway whereas Route- 2 might be a less maintained state road).The economic assistance offered by infrastructure are rated and prioritized through pairwise comparison method using the relative scale as explained earlier. The infrastructures are rated for their assistance offered to a specific activity and are normalized with respect to the best score.

The existing social and economic contribution assessment is made on the basis of rating provided to infrastructure or combination of infrastructure alternates. A contribution is defined as the assistance provided by an infrastructure in supporting a social/economic function/activity of a community/industry. It is assumed that, each critical infrastructure has a $100 \%$ serviceability level before flood situation. Critical infrastructures are damaged by the flood impacts which affect their serviceability level. Serviceability level can be assessed using its vulnerability level towards flood impacts. For this research, vulnerability has been defined as threats or real hazards to industries or communities in disaster situations that can vary according to the conditions of infrastructure (Oh et al. [19]). The level of vulnerability is measured in terms of probability as the vulnerability of critical infrastructure against floods based on the infrastructure health, its characteristics and flood level. This implies that an infrastructure having a high vulnerability level is likely to achieve a low level of serviceability after a flood impact and vice versa.

Activities can be performed through more than one infrastructure alternate if available (Fig. 5). The calculation is focused on activity shipping. It can be performed using two alternates:

- Option-1: Route-1 + Highway A

- Option-2: Route-2 + Highway A

However, the benefits offered by both options will be different. Using the pairwise comparison method, the alternates are rated for the economic assistance offered infrastructure options will be the best economic assistance offered in a pre-flood situation. Therefore, the "best" infrastructure option will help in sustaining depending activity at maximum economic assistance in any give 


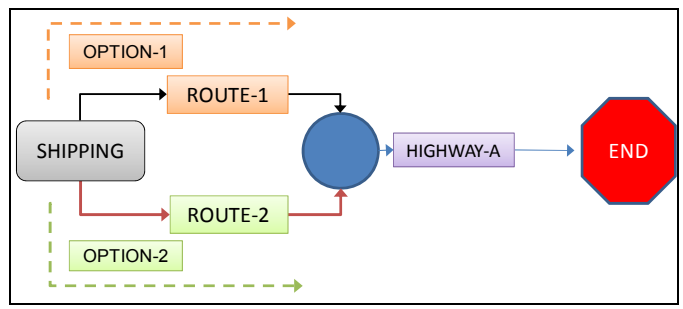

Figure 5: $\quad$ Infrastructure options for sustaining shipping.

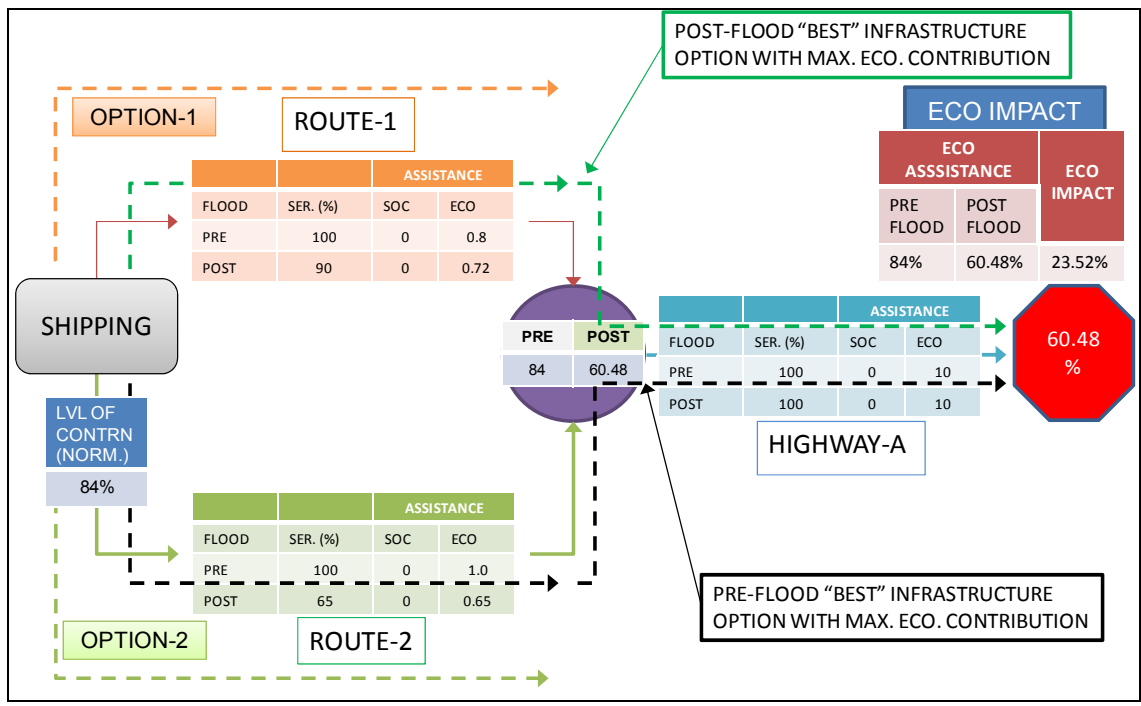

Figure 6: $\quad$ Sample impact assessment.

situation. Option-2 provides the maximum economic assistance of $84 \%$ to shipping when compared to option-1 (Fig. 6).

However, after the flood hits the town, the critical infrastructure gets damaged and their level of serviceability is reduced. This reduction is transferred to activities of industry $\mathrm{A}$ as a drop in economic assistance offered by critical infrastructure. It is assumed that reduction in assistance offered to an activity is proportional to reduction in the serviceability level of critical infrastructure. After the disasters, Route 1, Route 2 and Highway 1 achieve a new level of serviceability which influences the economic assistance offered to shipping (Fig. $6)$.

It is observed that due to the change in serviceability level of option-1 and option-2, economic contribution available for activity shipping changes considerably. Option-1 becomes the "best" infrastructure option in post-flood situation due to reduced level of serviceability of related critical infrastructure. Economic contribution of shipping drops down to $60.48 \%$. 


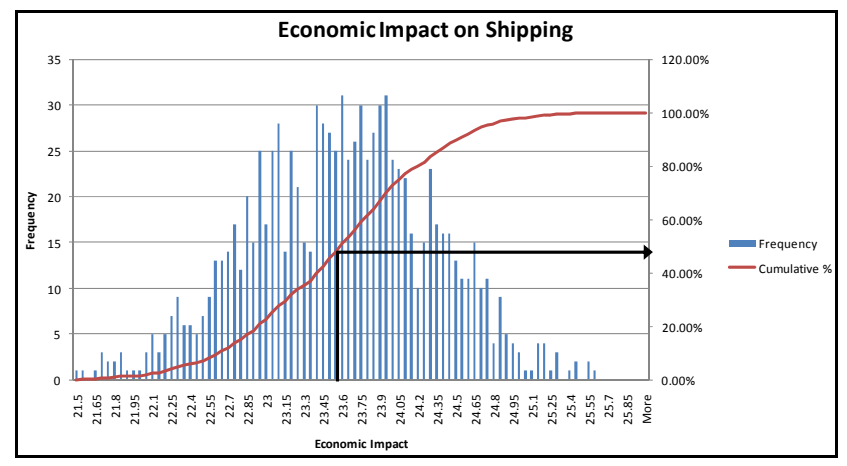

Figure 7: $\quad$ Economic impact for shipping.

The reduction in economic contribution due to reduced level of serviceability for critical infrastructure is considered as economic impact for the activity. The economic impact is $23.52 \%$ due to reduction in serviceability level of critical infrastructure. Similarly, the economic impact for other activities such as production, storage, etc., can be calculated and when combined together will provide the overall economic impact for industry A.

The loss in contribution for an activity and/or a node (e.g., Industry A in Fig. 4) would vary according to the changing level of damage to the associated infrastructure. Simpson et al. [23] have suggested the use of Monte Carlo Simulation in case of sparse or missing data for generating results. Communities, industries and infrastructure and their interrelationship are unique and thus to generate results over a large range, Monte Carlo simulation will be helpful.

Therefore, Monte Carlo Simulation Method would be used to establish the level of severity under these varying conditions accounting for the criticality, vulnerability, and loss of efficiency. As shown in the sample simulation results of Figure 7 (for economic impact), the cumulative distribution function indicates that there is $48 \%$ probability that activity shipping would have a $23.52 \%$ or less economic impact due to reduced level of serviceability of related critical infrastructure.

\section{Conclusion}

The proposed framework provides a simple holistic approach to assess the social and economic impact on communities and industries due to failure of services of related critical infrastructure. The analysis is based on the interrelationship between activities of communities and industries and critical infrastructure. Relevant ephemeral data having technical, social and economic aspect will be collected for assessing the social and economic impact for disaster impact analysis which will help in quick recovery response of communities and industries. The framework provides an approach for better understanding of flood impact on infrastructure and the associated industries and communities based on their interrelationship. Severity assessment will help in strategizing the 
recovery and rehabilitation of communities and industries based on the level of serviceability of related critical infrastructure.

\section{Acknowledgement}

This paper is based upon work supported by the National Science Foundation under Grant No. 0848016. Any opinions, findings, and conclusions or recommendations expressed in this material are those of the authors and do not necessarily reflect the views of the National Science Foundation.

\section{References}

[1] Burrus, Jr Robert T., Dumas, Christopher F., Farrell, Claude H., Hall, Jr William (2002). "Impact of Low-Intensity Hurricanes on Regional Economic Activity." Natural Hazards Review 3(3): 118-125.

[2] Chang, Stephanie E. (2003). "Evaluating Disaster Mitigations: Methodology for Urban Infrastructure Systems," Natural Hazards Review, Vol. 4, No. 4, November 1, pp 186-196

[3] Chang, Stephanie E., Svekla, Walter D., Shinozuka, Masanobu. (2002). "Linking infrastructure and urban economy: simulation of water-disruption impacts in earthquakes," Environment and Planning B: Planning and Design 2002, Vol 29, pp 281-301

[4] Cutter, Susan L., Boruff, Bryan J., Shirley, W. (2003). "Social Vulnerability to Environmental Hazards," Social Science Quarterly (Blackwell Publishing Limited) 84(2): 242-261.

[5] Dwyer, A., Zoppou, C., Nielsen, O., Day, S., Roberts, S. (2004). Quantifying Social Vulnerability: A methodology for identifying those at risk to natural hazards. Geoscience Australia. 14.

[6] Hastak, M., Shaked., A. (2000). "ICRAM-1: Model for International Construction Risk Assessment," Journal of Management in Engineering, Vol. 16, No. 1, January/February 2000, pp. 59-69.

[7] Hiete, M., Merz, M. (2009). "An indicator framework to assess the vulnerability of Industrial sectors against indirect losses," Proceedings of the $6^{\text {th }}$ International ISCRAM Conference, Gothenburg, Sweden, May 2009.

[8] Lian, Chenyang, Santos, Joost R., and Haimes, Yacov Y. (2007). "Extreme Risk Analysis of Interdependent Economic and Infrastructure Sectors," Risk Analysis, Vol. 27, No. 3, 2007, pp1053-1064

[9] Lin, Shuyeu, Shaw, Daigee, Ho, Ming-Chou. (2008). "Why are flood and landslide victims less willing to take mitigation measures than the public?" Natural Hazards 44(2): 305-314.

[10] Lindell, Michael, K., Prater, Carla, S. (2003). “Assessing Community Impacts of Natural Disasters," Natural Hazards Review, Vol. 4, No. 4, November 1, pp 176-185 
[11] Mantell, N. (2005). "Book Review: Modeling Spatial and Economic Impacts of Disasters, 2004. Advances in Spatial Science Series." Journal of Regional Science 45(3): 633-635.

[12] McDaniels, Timothy, Chang, Stephanie, Peterson, Krista, Mikawoz, Joey, and Reed, Dorothy. (2007). "Empirical Framework for Characterizing Infrastructure Failure Interdependencies," Journal of Infrastructure Systems, Vol. 13, No. 3, September 1, 2007, pp 175-184

[13] Moteff J., C., C., J., Fischer. (2003). Critical Infrastructures: What Makes an Infrastructure Critical? Library of Congress Washington DC Congressional Research Service.

[14] Munich-Re (2007). Topics. Annual Review: Natural Catastrophes 2006, Munich Reinsurance Group, Geoscience Research Group, Munich Germany.

[15] Oh, E. H. (2008). "Identification of the Impact of Critical Infrastructure on Associated Industries: Analysis of a Flood Disaster Event," Master's Thesis: Purdue University, Indiana, USA.

[16] Oh, E. H. and Hastak, M. (2008). "Impact Analysis of Natural Calamities on Infrastructure and Industries," Proceedings of the 4th i-REC conference, April 30-May 2, 2008, Christchurch, New Zealand.

[17] Oh, E. H., Deshmukh, A. and Hastak, M. (2009). "Infrastructure Risk Management in Preparedness of Extreme Events," Proceedings of the ICCEM/ICCPM Conference, May 27-30, 2009, Jeju, Korea.

[18] Oh, E. H., Deshmukh, A. and Hastak, M. (2009). "Risk Assessment of Critical Infrastructure in Disaster Preparedness and Response," Proceedings of the 16th Annual Canadian Construction Research Forum, August 9-11, 2009 - Banff, AB

[19] Oh, E. H., Deshmukh, A., Hastak, M., and Dietz. J. E. (2009). “2008 Midwest Floods Impact Analysis on Critical Infrastructure, Associated Industries, and Communities," Proceedings of the NSF 2009 Conference, June 22-25, 2009, Honolulu, Hawaii.

[20] Picou, S., J., Cecelia, M., G., (2006). Community Impacts of Hurricane Ivan: A Case Study of Orange Beach, Alabama. Natural Hazards Center Quick Response 190.

[21] Rinaldi, Steven E, Peerenboom, James P., and Kelly, Terrence K. (2001). "Identifying, Understanding, and Analyzing Critical Infrastructure Interdependencies," IEEE Control System Magazine, Dec. 2001. Pp. 11-25

[22] Rose, A., Oladosu, G., Liao, S. (2007). "Business Interruption Impacts of a Terrorist Attack on the Electric Power System of Los Angeles: Customer Resilience to a Total Blackout," Risk Analysis, Vol. 27, No. 3, 2007, pp513-531

[23] Simpson, D., M., Rockaway, T., D., Weigel, T., A., Coomes, P., A., Holloman, C., O. (2005). "Framing a new approach to critical infrastructure modeling and extreme events," International Journal of Critical Infrastructures 1: 125-143.

[24] Tapsell, S., M., Penning-Rowsell, E., C., Tunstall, S., M., Wilson, T., L. (2002). "Vulnerability to Flooding: Health and Social Dimensions." 
Philosophical Transactions: Mathematical, Physical and Engineering Sciences 360(1796): 1511-1525.

[25] Wildasin, D. (2006). "Disasters: issues for state and federal government finances," Working paper No. 2006-07, Institute for Federalism and Intergovernmental Relations, University of Kentucky, Lexington, KY

[26] Yang, Zhang, Lindell, Michael, K., Prater, Carla, S. (2009). "Vulnerability of community businesses to environmental disasters." Disasters 33(1): 3857. 